\title{
Distribuição espacial de cupinzeiros de Cornitermes snyderi (Isoptera: Termitidae) e sua associação com teca
}

\author{
Otávio Peres Filho ${ }^{1}$, Jaqueline Costa de Souza ${ }^{1}$, Marcelo Dias de Souza ${ }^{2}$, Alberto Dorval ${ }^{1}$ \\ ${ }^{1}$ Universidade Federal do Mato Grosso, Departamento de Engenharia Florestal, Av. Fernando Corrêa da Costa, 2367, Boa Esperança, 78125-070, Cuiabá, MT, Brasil \\ ${ }^{2}$ Universidade Federal do Paraná, Departamento de Ciências Florestais, Rua Lothário Meissner, 900, Jardim Botânico, 80210-170, Curitiba, PR, Brasil.
}

\section{*Autor correspondente: \\ peres@ufmt.br}

Termos para indexação:

Dispersão

Cupim-de-monte

Indice de Morisita

Tectona grandis.

Index terms:

Dispersion

Mound-building termite

Morisita index

Tectona grandis.

Histórico do artigo:

Recebido em 25/06/2011

Aprovado em 24/04/2012

Publicado em 29/06/2012

doi: 10.4336/2012.pfb.32.70.59
Resumo - O objetivo deste estudo foi identificar a espécie de cupim, avaliar a relação de ocorrência de ninhos com a cultura de Tectona grandis (teca) e seus possíveis danos provocados por essa associação, sendo determinado o tipo da distribuição espacial dos cupinzeiros na área de estudo. $\mathrm{O}$ trabalho foi realizado no município de Porto Esperidião, estado de Mato Grosso, em um plantio de teca de 581,27 ha. Os cupinzeiros foram posicionados com auxílio de um GPS (Global Positioning System) para posterior avaliação da distribuição populacional, conforme o índice de Morisita. Os ninhos foram quantificados em diferentes classes de cotas altimétricas. Avaliou-se também a quantidade de ninhos presentes nas árvores, nas rebrotas e fora das árvores, bem como a influência desses ninhos no crescimento das árvores. Os cupins encontrados foram identificados como Cornitermes snyderi, cujos ninhos não afetaram o crescimento em relação à circunferência à altura do peito $(\mathrm{CAP})$ das árvores. A distribuição espacial dos termiteiros no plantio é agregada, binomial negativa. Não foi constatada a presença de danos nas árvores circundadas pelos ninhos.

\section{Spatial distribution of termite-nests of Cornitermes Snyderi (Isoptera: Termitidae) and its association with teak}

\begin{abstract}
The objectives of this study was identify the termite species, assess the relationship of the occurrence of nests with Tectona grandis (teak) and its possible damage caused by this association, being determined the type of spatial distribution of nests in the studying area. This work was conducted in the municipality of Porto Esperidião, State of Mato Grosso, Brazil, in the teak plantation with 581,27 ha. The nests were placed with a GPS (Global Positioning System), for further assessment of population distribution, according to the Morisita index. The nests were quantified in different altitudes classes. It was also evaluated the number of nests found in trees and regrowth in and out of trees, as well as the influence of these nests in tree growth. The termites found were identify as Cornitermes snyderi. The nests do not affect the growth in relation to the circumference at breast height of tree. The spatial distribution of termites in the planting is pooled, binomial negative. I was not observed damage in trees surrounded by nests.
\end{abstract}




\section{Introdução}

Os cupins são organismos detritívoros e representam um dos grupos dominantes da fauna de ecossistemas tropicais, tendo um papel importante na ciclagem de nutrientes e na formação do solo (Constantino, 2002). Os cupins do gênero Cornitermes constroem seus ninhos em forma de monte ou montículo, o que dificulta ou impossibilita os tratos culturais bem como seu controle. Segundo Valério et al. (1998), os cupins de monte trazem danos indiretos, pois os cupinzeiros podem abrigar animais peçonhentos, dificultar a movimentação de máquinas e animais, e depreciar a propriedade, conferindo-lhe um aspecto de abandono.

A distribuição geográfica desses cupins está associada, principalmente, às florestas tropicais e cerrados da América do Sul e em todo o Brasil, podendo ser encontrados em diferentes habitats inclusive em pastagens (Constantino, 1999). O gênero Cornitermes constrói seus ninhos epígeos (sobre o solo) em diversos tipos de habitats, incluindo floresta, cerrado, campos e principalmente pastagens (Cancello, 1989).

Alguns estudos relatam que os cupins são diretamente afetados pelas alterações antrópicas e as devastações do cerrado por práticas agrícolas, tornando-se pragas devido aos desequilíbrios ecológicos (Núñez, 2010; Núñez, et al., 2011). Dentre as espécies de maior abundância do gênero Cornitermes destacam-se Cornitermes snyderi Emerson (1952) e Cornitermes cumulans (Kollar, 1832). Czepak et al. (2003) constataram que das 24 espécies de cupins coletadas no cerrado de Goiás, cerca de 58,9\% dos indivíduos eram da espécie C. snyderi. Este número pode estar relacionado, segundo esses autores, por esse gênero ser comumente encontrado em áreas abertas com pastagens de uso intenso e degradadas, o que resulta em números reduzidos de inimigos naturais, aumentando a reprodução de cupins de monte.

Apesar dos cupins serem muito estudados, há falta de estudos sobre a abundância, distribuição e diversidade dessas espécies existentes no cerrado. $\mathrm{O}$ estudo de faunas locais e sua dinâmica são importantes para o desenvolvimento de estratégias de manejo que garantam os serviços, especialmente no solo, e ao mesmo tempo evitem problemas com o surgimento de pragas (Constantino, 2005).

Os hábitos alimentares e danos provocados pelas espécies do gênero Cornitermes em viveiros florestais ou em mudas no campo são pouco conhecidos, apesar de serem citados nos levantamentos de pragas em diversas culturas como, por exemplo, plantações agrícolas e em pastagem (Cancello, 1989). Estes cupins são comumente encontrados em área de pastagens, constituindo-se uma exceção quando encontrado em plantios homogêneos com espécies florestais.

Em plantios de Tectona grandis L.f. pode ser constatada a presença de ninhos de cupins-de-monte. No entanto, no Brasil não há relatos da associação da teca com os térmitas. Em vista disso, objetivou-se nesse estudo identificar a espécie de cupim existente no local, analisar a relação de ocorrência dos ninhos com a cultura de teca, determinando os possíveis danos provocados por essa associação, bem como determinar a distribuição espacial dos ninhos em dois níveis de altitude.

\section{Material e métodos}

O trabalho foi realizado em 2009, na Fazenda Cacimba, localizada na rodovia BR 174, Km 117, sem número, município de Porto Esperidião, estado de Mato Grosso, com 581,27 ha plantados de Tectona grandis L.f. no ano de 2003. A propriedade está localizada entre as cotas altimétricas de 200 a $240 \mathrm{~m}$ em relação ao nível do mar.

Os cupins foram coletados quebrando-se os montículos com auxílio de um enxadão, acondicionados em álcool 70\% e transportados ao laboratório de Proteção Florestal da Universidade Federal de Mato Grosso, onde, posteriormente, foram enviados ao Museu de Zoologia, da Universidade de São Paulo, para identificação taxonômica. Foram quantificados todos os ninhos presentes nos 25 talhões da área de reflorestamento com teca (Figura 1).

Para a quantificação dos cupinzeiros presentes na propriedade, em relação à altitude, os cupins foram posicionados com auxílio de um GPS, sendo utilizadas as cotas altimétricas 200 — $220 \mathrm{~m}$ e $220 — 1240 \mathrm{~m}$ em relação ao nível do mar. Para determinar a distribuição dos cupins dentro da área de estudo foi utilizado o índice de Morisita (Morisita, 1959).

Para saber as diferenças significativas das arvores com e sem a presença de cupins em relação à circunferência à altura do peito (CAP), foram medidas as CAP das árvores com ninhos presentes nos troncos e de duas árvores subsequentes sem ninhos, da mesma linha, sendo calculado o valor médio, respeitandose um raio de no mínimo $6 \mathrm{~m}$ da árvore com ninho. 
O delineamento experimental foi inteiramente casualizado com dois tratamentos (com e sem a presença de ninho). Para esta análise foram amostrados apenas quatro talhões escolhidos ao acaso: 4A, 11, 15 e 18 , cujo número de repetições $(\mathrm{N})$ foi determinado de acordo com a quantidade de ninhos presentes em cada talhão. As médias foram comparadas estatisticamente entre si pelo teste $\mathrm{F}$, ao nível de $5 \%$ de probabilidade.

Foi realizado um delineamento em blocos casualizados para saber as diferenças significativas entre as quantidades de cupins presentes em três posições em relação a cada árvore: na base, nas rebrotas e fora da árvore (linhas do plantio) para cada talhão, exceto os talhões $4 \mathrm{~A}, 11,15$ e 18 , constituindo três tratamentos com 21 blocos. Os dados obtidos foram submetidos à análise de variância (ANOVA), sendo transformados pela fórmula: $\operatorname{arcsen} \sqrt{X / 100}$ , para garantir a normalidade. As médias foram comparadas entre si pelo teste Tukey, ao nível de 5\% de probabilidade. Todas as análises estatísticas foram executadas através do software Assistat, versão 7.6 beta (Silva \& Azevedo, 2002).

Amostras de solo dos talhões estudados foram coletadas na profundidade $0-20 \mathrm{~cm}$, onde foi feito um estudo de correlação significativa pelo método Pearson entre matéria orgânica, teor de areia, teor de argila, $\mathrm{Ca}$, $\mathrm{Mg}, \mathrm{K}$, presença de cupim e ausência de cupim, em relação ao CAP das árvores dos talhões 4A, 11, 15 e 18.

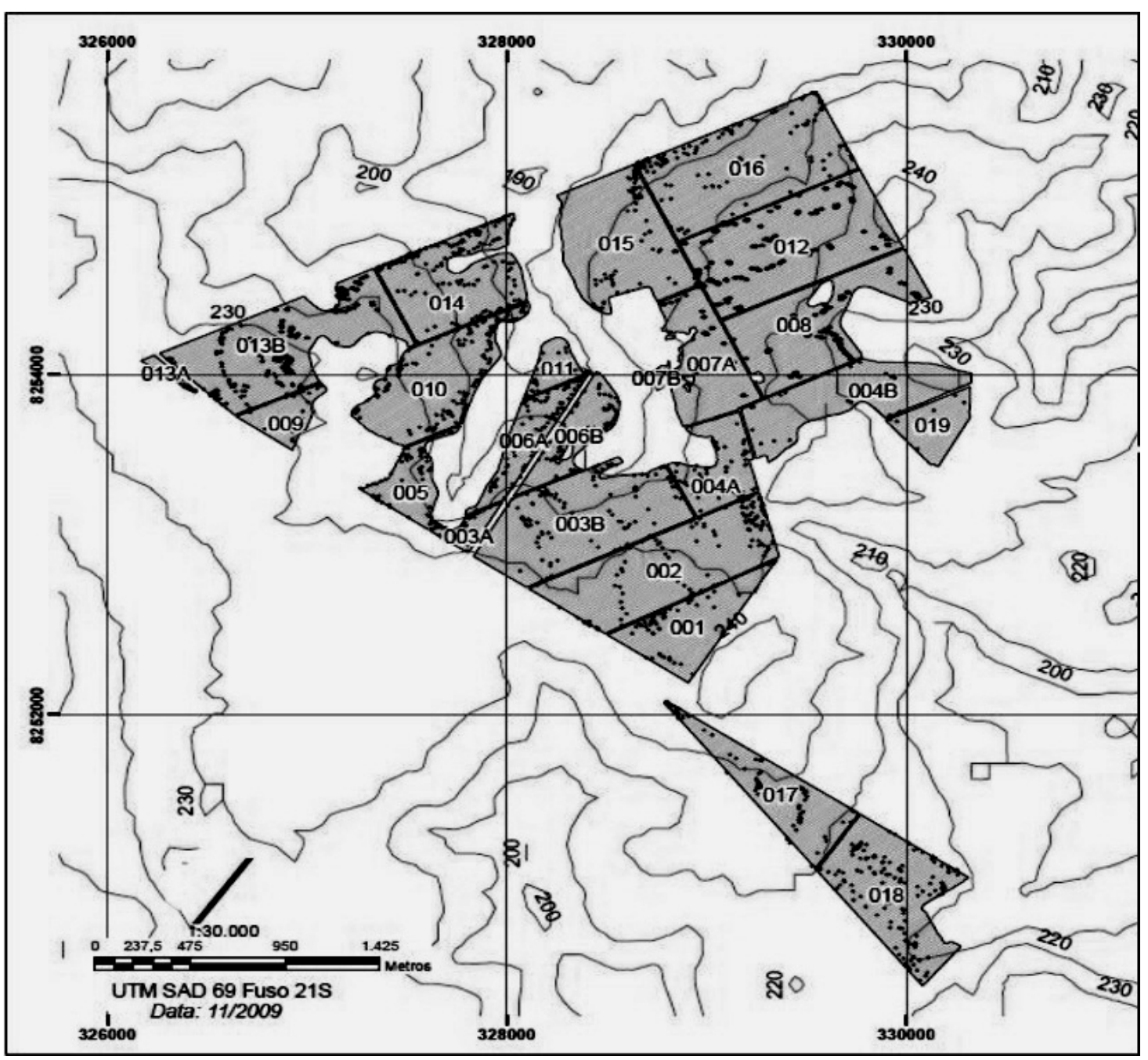

Figura 1. Mapa de localização dos talhões amostrados em Porto Esperidião, MT, 2009. 


\section{Resultados e discussão}

Os cupins coletados foram identificados como Cornitermes snyderi Emerson (1952) (Isoptera: Termitidae), e em apenas um montículo foi constatada a espécie Syntermes molestus (Burmeister, 1839), porém, essa espécie que habita ninhos subterrâneos, pode, eventualmente, ocupar ninhos das espécies do gênero Cornitermes.

\section{Quantidade de cupinzeiros por talhão}

Foram encontrados 2.112 montículos, sendo que o talhão 13B apresentou maior quantidade de cupinzeiros com o total de 403 ninhos, seguido dos talhões 18, 14, 12 e 10 com 158, 156, 151 e 144 cupinzeiros, respectivamente. Esses números podem estar relacionados com a localização dos talhões na área do plantio, pois se encontram entre as cotas altimétricas mais elevadas da propriedade $(220-1240 \mathrm{~m})$, além de estarem próximos do limite da propriedade que é circundada por pastagem. Essa proximidade pode propiciar uma maior ocorrência, uma vez que os cupins-de-monte encontram-se associados às pastagens.

Por se tratar de povoamento equiâneo, não existe a possibilidade de haver relação entre o número de cupinzeiros encontrados e a idade das árvores. Toda a área já foi submetida ao primeiro desbaste seletivo, acarretando um aumento na biomassa depositada sobre o solo, como, cepas, galhos e folhas. De acordo com Bignell \& Eggleton (2000), essa disposição propicia condições ideais para o estabelecimento de algumas espécies, pois a serapilheira, na forma de galhos, ramos e folhas, é uma fonte de alimentos para os cupins das subfamílias Macrotermitinae, Apicotermitinae, Termitinae e Nasutitermitinae (Família Termitidae). Portanto, o material seco acumulado no solo torna-se alimento para os térmitas, criando condições favoráveis de estabelecimento e sobrevivência.

Os talhões que apresentaram menores quantidade de montículos nas cotas $200 \longrightarrow 220 \mathrm{~m}$ foram o $6 \mathrm{C}$ e 7B com 7 e 19 ninhos, respectivamente, na qual fazem divisa com a reserva legal, assim como o 4B e o 19, nas cotas $220-1240$, com 17 e 8 cupinzeiros, respectivamente (Figura 2).

\section{Quantidade de cupinzeiros em relação às cotas altimétricas e distribuição espacial dos cupinzeiros (índice de Morisita)}

A maior quantidade de cupinzeiros encontrados na propriedade localiza-se nas bordas dos talhões e entre as cotas altimétricas de $220 — 240 \mathrm{~m}$, com o total de 1.292 montes (Figura 3A), quantidade superior ao número de cupins encontrado nas cotas altimétricas de $200-1220$ m que foi de 820 montes (Figura 3B), vale ressaltar que a cota 220 - $240 \mathrm{~m}$ apresenta maior número de talhões. Os dados obtidos reforçam as informações encontradas por Oliveira et al. (2003) que observaram uma diminuição na riqueza de espécies e abundância de colônias de térmitas, ao longo do gradiente de altitude, havendo espécies que ocorreram exclusivamente nas partes mais altas, entre elas C. snyderi. Essa variação, segundo esses autores, indica a possibilidade da existência de uma composição de espécies da ordem Isoptera como uma das características dos campos rupestres.

De acordo com o resultado obtido pelo índice de Morisita $\left(I_{\sigma}=1,8976\right)$ a distribuição é do tipo agregada ou também denominada de ocorrência em focos ou reboleiras. Segundo Nakano et al. (1981), a distribuição de ninhos de insetos sociais como cupins e formigas apresenta distribuição regular, isto é, binomial, porém o presente trabalho contraria esses dados sendo, portanto, binomial negativa. Este fato pode estar associado à disponibilidade de alimento que em um plantio florestal difere das condições encontradas em ambientes naturais.

Influência da presença do cupim do montículo em relação à circunferência a altura do peito (CAP) das árvores e sua correlação com as características do solo

As árvores com ninhos de cupins presentes na base do tronco apresentavam maiores diâmetros quando comparado com as árvores sem a presença dos ninhos, sendo diferentes estatisticamente entre si em todos os talhões. O talhão que apresentou maiores quantidades de cupins na base da árvore $(\mathrm{N})$ foi o 18 , com 25 ninhos, já os talhões $4 \mathrm{~A}, 15$ e 11 obtiveram 23,20 e 8 , respectivamente (Tabela 1 ). As árvores com a presença dos ninhos podem estar sendo beneficiadas nutricionalmente, pela associação cupim/árvore.

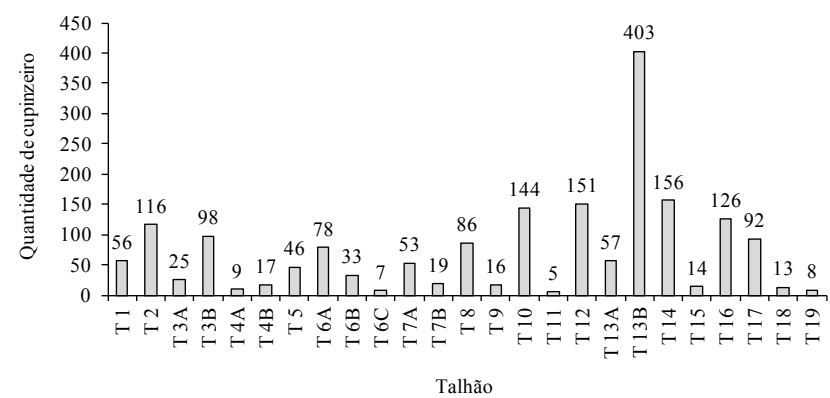

Figura 2. Quantidade de cupinzeiros coletados por talhão em Porto Esperidião, MT, 2009. 


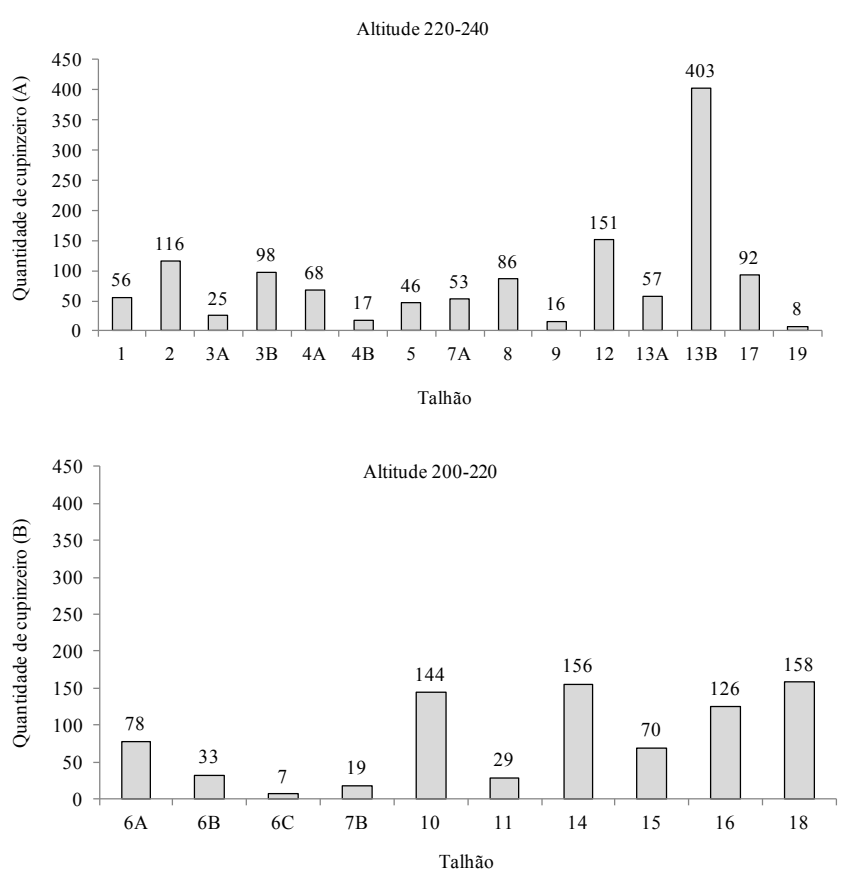

Figura 3. Quantidades de cupins em (A) cotas altimétricas de 220 - $240 \mathrm{~m}$ e em (B) cotas altimétricas de $200 \mathrm{~m}-\mathrm{I} 220$ m, em Porto Esperidião, MT, 2009.

Tabela 1. Médias da circunferência à altura do peito (CAP), das árvores com e sem cupinzeiro nos talhões amostrados em Porto Esperidião, MT, 2009.

\begin{tabular}{ccccc}
\hline \multirow{2}{*}{ Árvores } & \multicolumn{4}{c}{ Talhões } \\
\cline { 2 - 5 } & $\mathbf{4 A}$ & $\mathbf{1 1}$ & $\mathbf{1 5}$ & $\mathbf{1 8}$ \\
\hline Com cupim & $71,44 \mathrm{a}$ & $71,47 \mathrm{a}$ & $54,72 \mathrm{a}$ & $69,36 \mathrm{a}$ \\
Sem cupim & $41,29 \mathrm{~b}$ & $43,23 \mathrm{~b}$ & $35,04 \mathrm{~b}$ & $41,48 \mathrm{~b}$ \\
\cline { 3 - 5 } $\mathrm{N}$ & 23 & 8 & 20 & 25 \\
$\mathrm{~F}$ & $60,15^{*}$ & $20,53^{*}$ & $30,54^{*}$ & $80,10^{*}$ \\
$\mathrm{CV}(\%)$ & 23,38 & 21,73 & 25,08 & 19,86 \\
\hline
\end{tabular}

Médias seguidas da mesma letra nas colunas não diferem estatisticamente entre si, ao nível de $5 \%$ de probabilidade pelo teste $\mathrm{F}$.

Segundo Peres Filho et al. (1990), o material cartonado é mais rico em nutrientes do que o solo local, devido ao acúmulo de matéria orgânica presente na parte central do cupinzeiro. Oenriquecimento do solo modificado pelos cupins está associado com aumento no teor de matéria orgânica, provavelmente devido à incorporação de resíduos vegetais e de material fecal e salivar com o solo durante a construção do cupinzeiro e escavações de galerias (Holt \& Coventry, 1982). Estes autores sugerem que a persistência de pequenas áreas de solo com melhor fertilidade, antes ocupadas por cupinzeiros, podem explicar locais com gramíneas mais viçosas em solos de menor fertilidade. Para Azevedo et al. (2008), áreas mais próximas aos cupinzeiros têm maior quantidade de biomassa vegetal (incrementada pelos nutrientes difundidos a partir dos cupinzeiros), que diminui, à medida que se afasta dos cupinzeiros.

\section{Quantidade de cupinzeiros nas bases das árvores, nas rebrotas e fora das árvores em cada talhão}

Analisando os talhões amostrados, pode-se perceber que o 13B foi o que apresentou maior número de cupinzeiros na base e na rebrota das árvores, com 81 e 284, respectivamente, e o que apresentou menor quantidade nas três posições foi o 6C (Figura 4).

A quantidade total de termiteiros presentes nas árvores foi de 908, nas rebrotas foi de 551 e fora das árvores foi de 328 , não havendo diferenças estatísticas em relação ao número de cupins presentes nas árvores e nas rebrotas (Tabela 2). Não houve diferenças significativas entre os blocos $\left(\mathrm{F}=0,0072^{\mathrm{ns}}\right)$.

A maior quantidade de cupinzeiros encontrados nas rebrotas, pode estar relacionada com o fato de que embaixo das árvores e próximo daquelas que foram cortadas há maior concentração de material em decomposição, o que pode ter atraído esses térmitas, pela abundância de alimento. Os talhões 13B e 16, conforme observado em campo possuíam maior quantidade de material orgânico depositado no solo que os demais. Segundo Bandeira (1985), áreas que apresentam maiores quantidades de materiais vegetais em decomposição podem apresentar maiores quantidades de cupins.

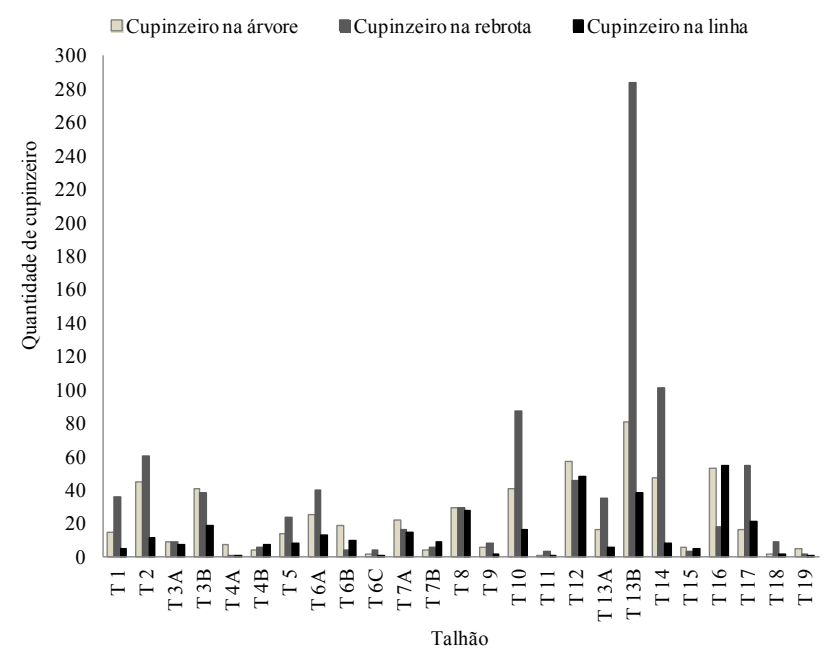

Figura 4. Quantidade de cupinzeiros na base da árvore, na rebrota e na linha em cada talhão, em Porto Esperidião, MT, 2009. 
Tabela 2. Quantidade média de ninhos na base da árvore, na rebrota e fora das árvores nos talhões amostrados, em Porto Esperidião, MT, 2009.

\begin{tabular}{ccc}
\hline Tratamentos & $\begin{array}{c}\text { Quantidade média de cupinzeiros nos } \\
\text { talhões (\%) }\end{array}$ \\
\hline Rebrota & $44,32 \pm 41,43$ & $\mathrm{a}$ \\
Árvore & $34,08 \pm 35,50$ & $\mathrm{ab}$ \\
Fora da árvore & $21,58 \pm 26,81$ & $\mathrm{~b}$ \\
F & \multicolumn{2}{c}{$9,84^{*}$} \\
DMS & 8,06 \\
CV $(\%)$ & 31,06 \\
\hline
\end{tabular}

${ }^{1}$ Dados transformados em $\operatorname{arcsen} \sqrt{X / 100}$

Médias seguidas da mesma letra não diferem estatisticamente entre si, ao nível de 5\% de probabilidade pelo teste Tukey.

\section{Correlação entre as características do solo com ausência ou presença de montículos}

A correlação foi maior entre a matéria orgânica e o CAP das árvores com cupins e sem cupins, 0,83 e 0,85 , respectivamente (Tabela 3 ), pois o crescimento das árvores está relacionado com os teores de matéria orgânica do solo. Os cupins enriquecem o solo incorporando a matéria orgânica nas baixas profundidades (Bandeira, 1985). As amostras foram retiradas entre 0 a $20 \mathrm{~cm}$ de profundidade e de acordo com Matricardi (1989), a matéria orgânica presente em teores elevados no solo provoca respostas altamente significativas sobre o crescimento da teca e mais eficientemente na região superficial do solo, onde grande parte do sistema radicular da teca está localizado.

Foi observada correlação negativa com o teor de areia e magnésio. Em relação ao teor de argila, houve uma correlação significativa maior com a presença de cupins do que sem a presença de cupins 0,65 e 0,41. Segundo Lee \& Wood (1971), solos arenosos em geral proporcionam pouca estabilidade para construção de túneis e ninhos subterrâneos pelos cupins, que aparentemente preferem solos mais argilosos. A seleção de partículas de argila pelos térmitas para a construção de seus montículos pode resultar no enriquecimento das proximidades dos ninhos com estas partículas mais finas na medida em que estes ninhos sofrem erosão, após seu abandono pelos cupins. Uma das consequências deste incremento de partículas finas é o aumento da quantidade de água disponível para as plantas (Konaté et al., 1999).

Não foi constatado o ataque de C. snyderi às árvores de $T$. grandis. As árvores não apresentavam nenhum sinal de dano pelos insetos, servindo apenas de estruturas para os montículos (Figura 5). De acordo com Leitãolima (2005), o ataque de cupins do gênero Cornitermes geralmente se da em muda ou em árvores mais nova, causando grandes prejuízos, dificilmente ocorrendo ataques em árvores adultas. Wilcken (1992) encontrou cupins do gênero Cornitermes sp. danificando as mudas de eucalipto, no município de Luiz Antônio, SP.

Sua infestação pode estar associada à pastagem que se encontra nas fazendas vizinhas à propriedade. Outra causa possível é pelo acúmulo de restos de vegetação deixada durante o processo do primeiro desbaste e também da grande biomassa gerada pela perda de folhas, característica dos plantios de teca, visto que esta espécie de cupim se alimenta deste tipo de vegetação. No entanto, a presença dos ninhos constitui problemas para as atividades florestais, tais como, desbaste ou desrama, deslocamento de máquinas e implementos florestais e outras técnicas do manejo silvicultural.

Tabela 3. Correlações significativas entre matéria orgânica, teor de areia, teor de argila, $\mathrm{Ca}, \mathrm{Mg}, \mathrm{K}$, presença de cupim e ausência de cupim, em relação ao CAP das árvores, em Porto Esperidião, MT, 2009.

\begin{tabular}{ccc}
\hline \multirow{2}{*}{ Características } & \multicolumn{2}{c}{ Correlação Significativa } \\
\cline { 2 - 3 } & Com cupim & Sem cupim \\
\hline Matéria orgânica & 0,83 & 0,85 \\
Teor de areia & $-0,58$ & $-0,34$ \\
Teor de argila & 0,65 & 0,41 \\
$\mathrm{Ca}$ & 0,11 & 0,41 \\
$\mathrm{Mg}$ & $-0,95$ & $-0,76$ \\
$\mathrm{~K}$ & 0,42 & 0,49 \\
\hline
\end{tabular}

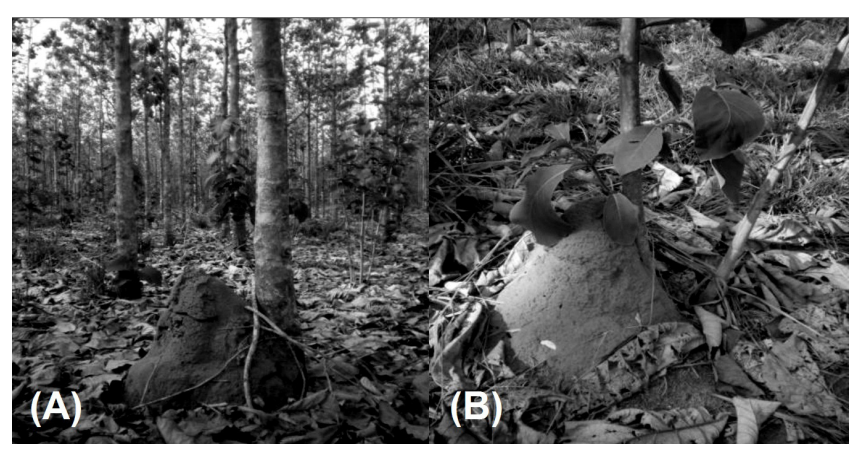

Figura 5. Montículo circundando a teca, em que aparentemente não apresenta danos na madeira, (A) na base da arvore e (B) na rebrota resultante do desbaste. Porto Esperidião, MT, 2009. 


\section{Conclusão}

A distribuição dos termiteiros no plantio é agregada, binomial negativa. A altitude influência na abundância dos ninhos, sendo os locais mais elevados os que apresentam maior quantidade de montículos. As áreas com maior quantidade de cupinzeiros circundando as bases das árvores são as que apresentam melhores condições de desenvolvimento para Tectona grandis em relação ao CAP.

\section{Agradecimentos}

À Dra. Eliana Marques Cancello, do Museu de Zoologia, da Universidade de São Paulo - USP, pela identificação dos cupins.

\section{Referências}

AZEVEDO, R. C.; CARDOSO, M. W.; ALMEIDA. M. C.; JUEN, L.; BARBOSA, D. C. F.; BRANDÃO FILHO D. O gradiente de nutrientes no solo gerado pela presença de cupinzeiros cria um gradiente de biomassa vegetal?. Anais do PPG - Ecologia e Evolução, UFG, p.20-24. 2008.

BANDEIRA, G. A. Cupinzeiros como fonte de nutrientes em solos pobres da Amazônia. Boletim do museu Paraense Emilio Goeldi: Zoologia. v.2, n.1, p39-48, 1985.

BIGNELL, D. E.; EGGLETON, P. Termites in ecosystems In: T. ABE, D.E. BIGNELL AND M. HIGASHI, Editors. Termites: Evolution, Sociality, Symbioses, Ecology, Kluwer Academic Publishers, Dordrecht, pp.363-387. 2000.

CANCELLO, E. M. Revisão de Procornitermes Emerson (Isoptera: Termitidae, Nasutitermitinae). Papéis Avulsos de Zoologia. São Paulo - SP. v.36, n.19, p.189-236. 1989.

CONSTANTINO, R. Chave ilustrada para identificação dos gêneros de cupins (Insecta: Isoptera) que ocorrem no Brasil. Papéis Avulsos de Zoologia. São Paulo - SP. v.40, n.25, p.387-448. 1999.

CONSTANTINO, R. The pest termites of South America: taxonomy, distribution and status. Journal of Applied Entomology. v.126, p.355-365. 2002.

CONSTANTINO, R. Padrões de diversidade e endemismo de térmitas no bioma cerrado. In: SCARIOT, A. O.; SILVA, J. C. S.; FELFILI, J. M. (Eds.) Biodiversidade, Ecologia e Conservação do Cerrado. Ministério do Meio Ambiente. 2005, p.319-333, 439p.

CZEPAK, C.; ARAÚJO, E. A. FERNANDES, P. M. Ocorrência de espécies de cupins de montículo em pastagens no estado de Goiás. Pesquisa Agropecuária Tropical. v.33, n.1, p.35-38, 2003.

HOLT, J. A.; COVENTRY, R. J. The effects of mound-building termites on some-chemical properties of soils in Northeastern Australia. In: Australasian conference on grassland invertebrate ecology 3, 1982, Adelaide. Proceedings. Adelaide: Government Printing Division, p. 313-319.
KONATÉ, S.; LE ROUX, X.; TESSIER, D.; LEPAGE, M. Influence of large termitaria on soil characteristics, soil water regime, and tree leaf shedding pattern in a west African savanna. Plant and Soil. Dordrecht. v.206, n.1, p.47-60, 1999.

LEE, K. E.; WOOD, T. G. Termites and soils. London, Academic press. London and New York, 1971, 251p.

LEITÃO-LIMA, P. S. Cornitermes cumulans Kollar, 1832 (Isoptera: Termitidae): preferência a diferentes substratos e avaliação de danos em plantas de eucalipto. 2005. $74 \mathrm{f}$. Tese (Doutorado em Agronomia) - Universidade Estadual Paulista "Júlio de Mesquita Filho". Botucatu - SP.

MATRICARDI, W. A. T. Efeitos dos fatores de solo sobre o desenvolvimento da teca (Tectona grandis L.f.) cultivada na grande Cáceres - Mato Grosso. 1989. 135 f. Dissertação (Mestrado em Ciência Florestal) - Universidade de São Paulo, Piracicaba - SP.

MORISITA, M. Measuring of the dispersion of individuals and analysis of the distributional patterns. Mem. Fac. Sci., Kyushi Univ. Fed. Biol. v.2, p.215-235, 1959.

NAKANO, O.; SILVEIRANETO, S.; ZUCCHI, R. A. Entomologia Econômica. Piracicaba, São Paulo: Livroceres Ltda., 1981, 314p.

NÚÑEZ, B. N. C. Diversidade e Distribuição da Termitofauna no Ecótone Cerrado/Caatinga no Sul do Piauí Frente à Expansão Agrícola. 2010. 81 f. Dissertação (Mestrado em Fitossanidade e Biotecnologia Aplicada). Universidade Federal Rural do Rio de Janeiro. Seropédica - RJ

NÚÑEZ, B. N. C.; LIMA, M. S. C. S.; MENEZES, E. B.; PEDERASSI, J. Ocupação de ninhos de cupins epígeos e arbóreos em fragmento de caatinga hipoxerófila em Bom Jesus-PI. Comunicata Scientiae. Teresina. v.2, n.3, p.164-169, 2011.

OLIVEIRA, A. R. G.; FREITAS, G. A.; CHAVES, E. C.; LIMA FILHO, G. F.; COSTA, D. A.; SANTOS, T.; CRISPIM, L. S.; BRANDÃO, D. Variação na Composição de Espécies e no Padrão de Riqueza e Abundância de Cupins ao Longo de uma Transição Cerrado - Campo Rupestre, no Morro Feio, Município de Hidrolândia, Goiás . VI Congresso de Ecologia do Brasil. Fortaleza, v.1, p.368-370, 2003.

PERES FILHO, O.; SALVADORI, J. R.; SANCHEZ, G.; NAKANO, O.; TERÁN, F. O. Componentes do material utilizado na construção do termiteiro de cupim-de-montículo. Pesquisa Agropecuária Brasileira. Brasília-DF, v.25, n.2, p.167-171, 1990.

SILVA, F. A. S.; AZEVEDO, C. A. V. Versão do programa computacional Assistat para o sistema operacional Windows. Revista Brasileira de Produtos Agroindustriais. Campina Grande, v.4, n.1, p.71-78, 2002.

VALÉRIO, J. R.; SANTOS, A. V.; SOUZA, A. P.; MACIEL, C. A. M.; OLIVEIRA, M. C. M. Controle químico e mecânico de cupins de montículo (Isoptera: Termitidae) em pastagens. Anais da Sociedade Entomológica do Brasil, Londrina, v.27, p. 125-131, 1998.

WILCKEN, C. F. Danos de cupins subterrâneos Cornitermes sp. (Isoptera: Termitidae) em plantios de Eucalyptus grandis e controle com inseticida no solo. Anais da Sociedade Entomológica do Brasil. v. 21, n. 3, p. 329-338, 1992. 
